\section{Ophthalmic Herpes Zoster Infection in Patients with Rheumatoid Arthritis Who Were Treated with Tocilizumab}

\section{To the Editor:}

Tocilizumab is a humanized IgG1 anti-interleukin 6 (anti-IL-6) receptor monoclonal antibody that inhibits both soluble and membrane-expressed IL-6 receptors, limiting multiple proinflammatory IL-6 activities through inhibition of the gp130 receptor pathway. Tocilizumab showed clinical efficacy in rheumatoid arthritis (RA) when used in monotherapy or with disease-modifying antirheumatic drugs.

We describe the first case of ophthalmic herpes zoster (HZ) in a patient with RA who was treated with tocilizumab.

The patient was a 64-year-old woman with seropositive erosive RA, successively treated with hydroxychloroquine, methotrexate (MTX), leflunomide, then with biologic therapies etanercept and adalimumab, without lasting efficacy. Tocilizumab $(8 \mathrm{mg} / \mathrm{kg} \mathrm{IV} /$ week) associated with MTX (10 mg/week) was then given, with good clinical and biological efficacy, without the need for steroids. After 9 months of tocilizumab treatment, she developed HZ duplex bilateralis, combining a right ophthalmic $\mathrm{HZ}$ (vesicles on the tip, side, and root of the nose) and a C4 metamere HZ with painful grouped erythematous vesicles at the anterior part of the left shoulder. HZ improved with local treatment, and valacyclovir $1 \mathrm{~g} /$ day orally, but relapses appeared after every tocilizumab injection despite dose reduction, and treatment had to be stopped 10 months later. Rituximab 500 $\mathrm{mg} /$ week was then given in association with valacyclovir $500 \mathrm{mg} /$ day, without $\mathrm{HZ}$ relapse after 12 months of treatment.

Several adverse events have been observed with tocilizumab, but $\mathrm{HZ}$ is infrequent, and to our knowledge this is the first report of ophthalmic $\mathrm{HZ}$ with duplex bilateralis in a patient with RA who was treated with tocilizumab.

$\mathrm{HZ}$ is caused by the reactivation of latent varicella zoster virus (VZV) maintained after primary infection throughout life in the spinal dorsal root ganglia of the cranial nerves. Virus replication later depends upon several conditions, and protection from reactivation of VZV from latency seems to depend on VZV-specific T cell-mediated immunity that is elicited during primary infection and declines with advancing age.

The role of IL-6 in clearance of infections with viruses has been demonstrated through studies with IL-6-deficient mice ${ }^{1}$. It has been demonstrated that IL-6 is also required for an optimal immune response after ocular herpes simplex virus type 1 (HSV-1) infection ${ }^{2}$ and is considered to contribute to resistance against $\mathrm{HSV}^{3}$.

In RA, reports conflict about the influence of treatments. HZ has been observed in patients receiving specific treatments including corticosteroids and MTX. But according to Wolfe, et $a l^{4}$, MTX might not be involved. VZV reactivation with anti-tumor necrosis factor- $\alpha$ is not well documented. The severity of the disease possibly increases the risk. In the report from Wolfe, et $a l^{4}$, biologic agents are not risk factors. Strangfeld, et al ${ }^{5}$ and Wendling, et $a l^{6}$ observed that VZV reactivation seems to happen mainly with monoclonal antibodies. In the German biologics register RABBIT $^{5}$, a significant risk is observed with monoclonal antibodies, without significant association for etanercept.

One case of $\mathrm{HZ}$ reactivation out of 157 patients with RA treated with tocilizumab is reported in the SAMURAI study ${ }^{7}$. Seven cases are reported by the same group in the STREAM study ${ }^{8}$, out of 143 patients with RA who were treated with tocilizumab. Those cases are classified as serious events, in addition to 12 serious infections. A particular severity is not mentioned in either report, and in our case the effect was mild, with moderate pain and benign course without development of any keratitis, scarring, or vision troubles.

The phenomenon of $\mathrm{HZ}$ occurring in 2 noncontiguous, widely separated dermatomas is referred to as zoster duplex unilateralis or bilateralis, depending on whether 1 half or both halves of the body are involved. Such cases of bilateral involvement are rare, and moreover, synchronous HZ involving 2 widely separated regions, as in our patient, is even rarer, with an incidence below $0.5 \% 9$

Our case of $\mathrm{HZ}$ in a patient with RA who was treated with tocilizumab must be considered within the context of $\mathrm{HZ}$ in immunodepressed patients, but with some particular features. The effect of tocilizumab is apparent, taking into account relapses at every tocilizumab treatment and resolution when tocilizumab is stopped.

Rituximab's effect is on B lymphocytes, which do not seem to be involved in HZ. That could explain the absence of relapse during rituximab treatments. In fact, rare cases of $\mathrm{HZ}$ during rituximab treatments exist, but they happen also in patients receiving chemotherapy.

The course of the condition in our case was benign. Reasons for this are not clear but we must consider that IL-6 plays an important role in allodynia and hyperalgesia after peripheral nerve injury in rodents ${ }^{10}$, and seems higher in patients with postherpetic neuralgia ${ }^{11}$. It could be that IL-6 inhibition with tocilizumab in RA contributes to the benign course of HZ.

CHRISTIAN ROUX, MD; VERONIQUE BREUIL, MD; CHRISTINE ALBERT, MD; VACINE ALLAM, MD; CHRISTIAN GRISOT, MD; HASNA CHAMI, MD; VIRGINIE DASILVA, MD; LIANNA EULLER-ZIEGLER, MD, Rheumatology Department, Academic Hospital l'Archet 1, Nice, and University of Nice Sophia Antipolis, Nice, France. Address correspondence to Dr. C. Roux, Hopital l'Archet 1, Route de Saint Antoine de Ginestiere, 06100 Nice, France.

E-mail: roux101fr@yahoo.fr

\section{REFERENCES}

1. Kopf M, Baumann H, Freer G, Freudenberg M, Lamers M, Kishimoto T, et al. Impaired immune and acute-phase responses in interleukin-6-deficient mice. Nature 1994;368:339-42.

2. LeBlanc RA, Pesnicak L, Cabral ES, Godleski M, Straus SE. Lack of interleukin-6 (IL-6) enhances susceptibility to infection but does not alter latency or reactivation of herpes simplex virus type 1 in IL-6 knockout mice. J Virol 1999;73:8145-51.

3. Paludan SR. Requirements for the induction of interleukin- 6 by herpes simplex virus-infected leukocytes. J Virol 2001;75:8008-15

4. Wolfe F, Michaud K, Chakravarty EF. Rates and predictors of herpes zoster in patients with rheumatoid arthritis and non-inflammatory musculoskeletal disorders. Rheumatology 2006;45:1370-5.

5. Strangfeld A, Listing J, Herzer P, Liebhaber A, Rockwitz K, Richter C, et al. Risk of herpes zoster in patients with rheumatoid arthritis treated with anti-TNF-alpha agents. JAMA 2009:301:737-44

6. Wendling D, Streit G, Toussirot E, Prati C. Herpes zoster in patients taking TNF alpha antagonists for chronic inflammatory joint disease. Joint Bone Spine 2008;75:540-3.

7. Nishimoto N, Hashimoto J, Miyasaka N, Yamamoto K, Kawai S, Takeuchi T, et al. Study of active controlled monotherapy used for rheumatoid arthritis, an IL-6 inhibitor (SAMURAI): evidence of clinical and radiographic benefit from an $\mathrm{x}$ ray reader-blinded randomised controlled trial of tocilizumab. Ann Rheum Dis 2007;66:1162.

8. Nishimoto N, Miyasaka N, Yamamoto K, Kawai S, Takeuchi T, Azuma J. Long-term safety and efficacy of tocilizumab, an anti-interleukin-6 receptor monoclonal antibody, in monotherapy, in patients with rheumatoid arthritis (the STREAM study): evidence of safety and efficacy in a 5-year extension study. Ann Rheum Dis 2009;68:1580-4.

9. Shin BS, Seo HD, Na CH, Choi KC. Case of herpes zoster duplex bilateralis. J Dermatol 2009;36:95-7.

10. Arruda JL, Sweitzer S, Rutkowski MD, DeLeo JA. Intrathecal anti-IL-6 antibody and IgG attenuates peripheral nerve injury-induced mechanical allodynia in the rat: possible immune modulation in neuropathic pain. Brain Res 2000;879:216-25.

11. Zhu SM, Liu YM, An ED, Chen QL. Influence of systemic immune and cytokine responses during the acute phase of zoster on the development of postherpetic neuralgia. J Zhejiang Univ Sci B 2009; 10:625-30.

J Rheumatol 2011;38:2; doi:10.3899/jrheum.100737 